OPEN ACCESS

Edited by:

Na Luo,

Nankai University, China

Reviewed by:

Gabriella Castoria,

Second University of Naples, Italy

Damien Leach,

Imperial College London,

United Kingdom

*Correspondence:

Ronghao Wang

ronghao_wang@swmu.edu.cn

Rongyang Dai

dryrun2502@163.com

${ }^{\dagger}$ These authors have contributed equally to this work

Specialty section:

This article was submitted to Molecular and Cellular Pathology,

a section of the journal

Frontiers in Cell and Developmental

Biology

Received: 23 June 2021 Accepted: 06 September 2021

Published: 06 October 2021

Citation:

Tang Q, Cheng B, Dai R and Wang R (2021) The Role of Androgen Receptor in Cross Talk Between Stromal Cells and Prostate Cancer Epithelial Cells.

Front. Cell Dev. Biol. 9:729498. doi: 10.3389/fcell.2021.729498

\section{The Role of Androgen Receptor in Cross Talk Between Stromal Cells and Prostate Cancer Epithelial Cells}

\author{
Qianyao Tang ${ }^{1 t}$, Bo Cheng ${ }^{2 t}$, Rongyang Dai ${ }^{1 *}$ and Ronghao Wang ${ }^{1 *}$ \\ ${ }^{1}$ Department of Biochemistry and Molecular Biology, School of Basic Medical Sciences, Southwest Medical University, \\ Luzhou, China, ${ }^{2}$ Department of Urology, The Affiliated Hospital of Southwest Medical University, Luzhou, China
}

Prostate cancer ( $\mathrm{PCa}$ ) lists as the second most lethal cancer for men in western countries, and androgen receptor (AR) plays a central role in its initiation and progression, which prompts the development of androgen deprivation therapy (ADT) as the standard treatment. Prostate tumor microenvironment, consisting of stromal cells and extracellular matrix (ECM), has dynamic interactions with PCa epithelial cells and affects their growth and invasiveness. Studies have shown that both genomic and non-genomic AR signaling pathways are involved in the biological regulation of PCa epithelial cells. In addition, AR signaling in prostate stroma is also involved in $\mathrm{PCa}$ carcinogenesis and progression. Loss of AR in PCa stroma is clinically observed as PCa progresses to advanced stage. Especially, downregulation of AR in stromal fibroblasts dysregulates the expression levels of ECM proteins, thus creating a suitable environment for PCa cells to metastasize. Importantly, ADT treatment enhances this reciprocal interaction and predisposes stromal cells to promote cell invasion of $\mathrm{PCa}$ cells. During this process, AR in PCa epithelium actively responds to various stimuli derived from the surrounding stromal cells and undergoes enhanced degradation while elevating the expression of certain genes such as MMP9 responsible for cell invasion. AR reduction in epithelial cells also accelerates these cells to differentiate into cancer stem-like cells and neuroendocrine cells, which are AR-negative PCa cells and inherently resistant to ADT treatments. Overall, understanding of the cross talk between tumor microenvironment and PCa at the molecular level may assist the development of novel therapeutic strategies against this disease. This review will provide a snapshot of AR's action when the interaction of stromal cells and PCa cells occurs.

Keywords: PCa, AR, microenvironment, stroma, androgen deprivation therapy (ADT)

\section{INTRODUCTION}

Prostate cancer $(\mathrm{PCa})$ is a malignant growth of prostate epithelial cells, and it continuously causes severe mortality among men. According to a survey in 2020, an estimated 190,000 new cases of PCa are diagnosed and 33,000 associated deaths are reported worldwide (Siegel et al., 2020), suggesting an urgent need to identify effective therapeutic strategies against this disease. Given the fact that 
androgen receptor (AR) plays central roles in $\mathrm{PCa}$ carcinogenesis (Heinlein and Chang, 2004; Lonergan and Tindall, 2011), androgen deprivation therapy (ADT) is the mainstream treatment for PCa, which is effective for 2-3 years before PCa progresses to castration-resistant PCa (CRPC; Ruizeveld de Winter et al., 1994; Henshall et al., 2001; Scher et al., 2004). The reactivation of $A R$ in $C R P C$, owing to gene amplification (Koivisto et al., 1997), gene mutation (Tilley et al., 1996), or the production of constitutively active AR variants (Nakazawa et al., 2014), makes it still a promising therapeutic target.

Androgen receptor, also called NR3C4 (nuclear receptor subfamily 3 , group C, member 4 ), is one member of the steroid and nuclear receptor superfamily and is encoded by the AR gene located at Xq11-12 (Tan et al., 2015). AR mainly contains four functional domains, as indicated in Figure 1: the aminoterminal domain (NTD; exon 1), DNA-binding domain (DBD; exons 2-3), hinge region (exon 4), and ligand-binding domain (LBD; exons 4-8). As a hormone-inducible transcription factor, $\mathrm{AR}$ is ubiquitously expressed in multiple tissues and is involved in various physiological and pathological events by controlling gene expression (Waghray et al., 2001; DePrimo et al., 2002). Genomic AR signaling in PCa is well studied: AR disassociates from its cytoplasmic chaperones such as HSP70 and translocates to the nucleus upon androgenic hormone binding, working as either homodimer or heterodimer to regulate its downstream genes such as PSA, FKBP5, and TMPRSS2, in order to provide survival signals for PCa growth (Figure 1; Smith and Toft, 2008). Of note, activation of non-genomic AR signaling is also critical to PCa development. An early study demonstrated that AR in both prostatic smooth muscle cells and prostatic epithelial cells rapidly responded to androgen stimulation (Peterziel et al., 1999) and interacted with non-receptor tyrosine kinase Src (Migliaccio et al., 2000; Castoria et al., 2017). This interaction impaired the inhibitory intramolecular binding of Src and allowed it in its active form to activate PI3K and MAPK signaling pathways, which promoted cell proliferation and cell invasion of PCa (Cai H. et al., 2011; Castoria et al., 2017). Although castration leads to a remarkable decline of AR activity, AR utilizes various novel ways to escape androgen ablation and continues to support PCa growth in castration-resistant stage (Figure 2). For instance, upregulated EGF and IGF in CRPC could activate AR transactivation. Mechanistically, Src responded to EGF stimulation and phosphorylated AR at the residue of tyrosine 534, leading to AR activation (Migliaccio et al., 2005; Liu et al., 2010). IGF-stimulated AKT and ERK1/2 signaling pathways were directly responsible for AR activation (Wu et al., 2006). In addition, elevated cytokines in CRPC such as IL-6 or IL-8 also had the capacity to activate AR signaling via MAPK and JAK/STAT3 signaling pathways (Chen et al., 2000; Seaton et al., 2008). Studies also revealed that AR mutation including aberrant AR splicing and AR gene amplification were frequently (1030\%) observed in CRPC patients (Visakorpi et al., 1995; Tilley et al., 1996; Koivisto et al., 1997), which allowed it to be active even under castrated conditions, effectively conferring androgen independence to AR.

Prostate cancer is a malignant mass infiltrated with endothelial cells, bone marrow stem cells, fibroblasts, and immune cells
(Sejda et al., 2020; Thienger and Rubin, 2021). Evidence suggested that the infiltration of these cells increased as PCa progressed to the CRPC stage. These stromal cells provide cytokines and growth factors to drive PCa progression. Clinical evidence indicated that stromal $\mathrm{AR}$ was a protective factor for $\mathrm{PCa}$ patients as its expression was inversely related to poor PCa outcomes including tumor stage, metastasis, cancer relapse, and cancer-related death (Olapade-Olaopa et al., 1999; Henshall et al., 2001; Ricciardelli et al., 2005; Li et al., 2008; Wikstrom et al., 2009; Leach et al., 2015). In contrast, AR in PCa epithelium acted as a tumor-promoting factor to control PCa development. Therefore, comprehensive knowledge of AR's role in the cross talk between PCa and its surrounding stromal component is necessary for scientists to better understand this disease.

\section{ANDROGEN RECEPTOR INHIBITION AS A STANDARDIZED TREATMENT FOR PROSTATE CANCER}

Androgen receptor inhibition is the major way to treat $\mathrm{PCa}$, and AR-targeted therapies are listed in Table 1. ADT has been the mainstay treatment for PCa patients in past decades, which includes surgical and chemical castration. Surgical castration refers to one operation in which the entire testes is removed to ablate androgen synthesis, while chemical castration utilizes various types of compounds to antagonize AR signaling pathway in PCa. Leuprorelin and triptorelin are clinically used as LHRH agonists to fulfill androgen deprivation (Crawford and Hou, 2009; Lepor and Shore, 2012). Mechanistically, LHRH agonist treatment leads to LHRH downregulation and eventually inhibits pituitary production of follicle-stimulating hormone (FSH) and luteinizing hormone ( $\mathrm{LH})$, two important hormones responsible for androgen synthesis in testes, while LHRH antagonists such as degarelix and relugolix interact with LHRH receptor and impair the physiological binding of LHRH and its receptor, reducing androgen synthesis. However, LHRH agonists and antagonists only block testes from producing androgens. Evidence show that $5-10 \%$ of androgens are generated from adrenal glands and they are sufficient to drive AR signaling (Montgomery et al., 2008), which facilitates the development of other compounds in order to reduce the synthesis of adrenal androgens. CYP17 is a key enzyme required for the biosynthesis of adrenal androgens so that its specific inhibitors such as abiraterone, TAK-700, and TOK-001 have been developed to treat CRPC patients who are resistant to LHRH agonists and antagonists (Schweizer and Antonarakis, 2012).

Of note, the castration level of androgen still has the ability to activate AR signaling and to support CRPC growth. To reach a deep AR inhibition, anti-androgens are developed to treat metastatic CRPC patients. They directly inhibit the binding of androgen to $\mathrm{AR}$ and to prevent $\mathrm{AR}$ nuclear translocation and the subsequent transactivation. However, first-generation anti-androgens such as bicalutamide cannot completely block AR activity due to their relatively low 

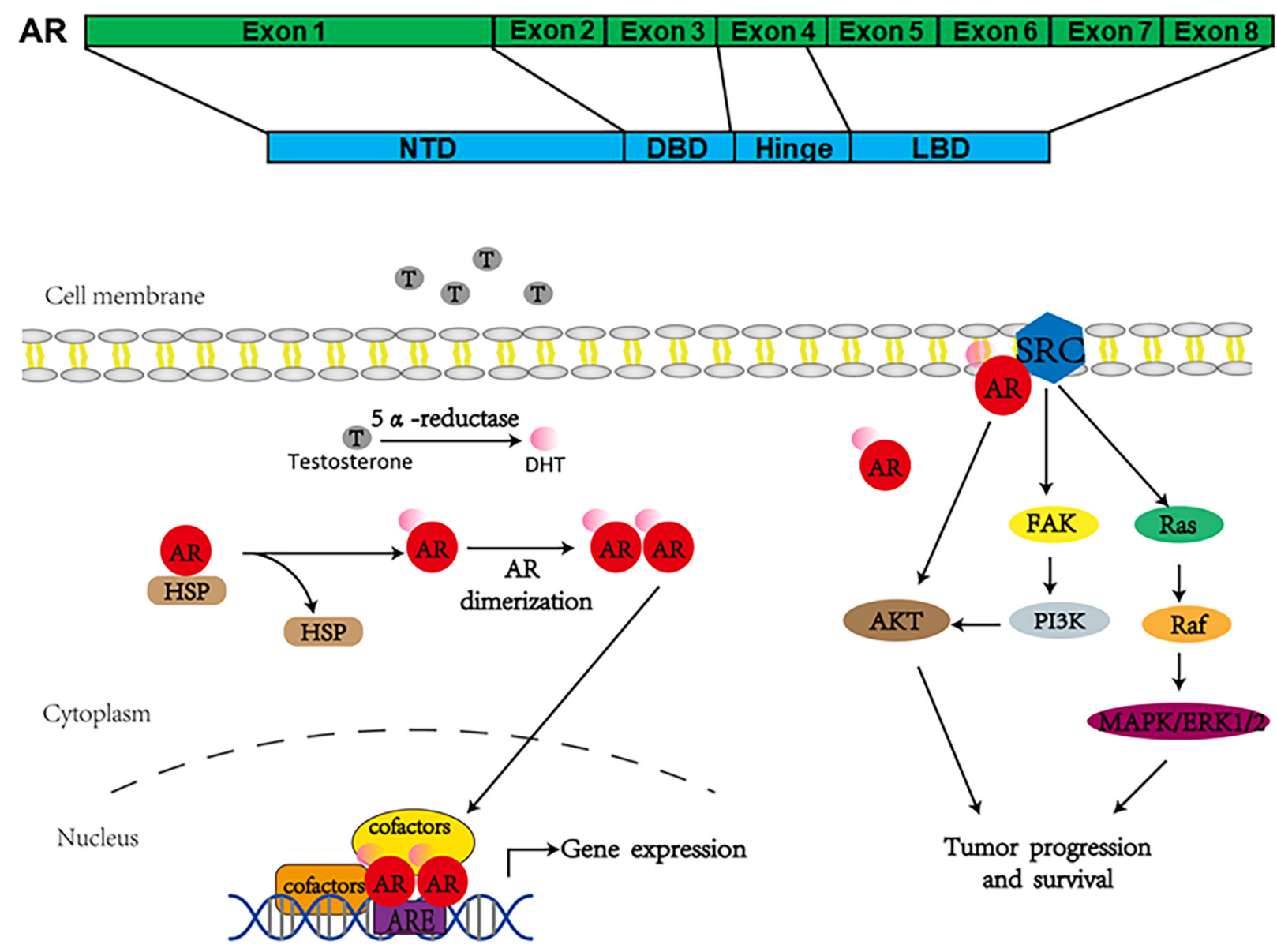

FIGURE 1 | Androgen receptor's structure and how it works to regulate gene expression.

affinity to AR. This leads to the emergence of secondgeneration anti-androgens in the standard treatment of metastatic CRPC patients. Enzalutamide is one of these second-generation anti-androgens and significantly improves patients' survival (Scher et al., 2010; Roumiguie et al., 2021). Overall, AR inhibition is the main strategy to prevent PCa development.

\section{ANDROGEN RECEPTOR SIGNALING IN CROSS TALK BETWEEN ENDOTHELIAL CELLS AND PROSTATE CANCER}

Endothelial cells are key builders of vascular structure, and their proliferation, migration, and remodeling are tightly associated with angiogenesis (Dudley, 2012). Early reports demonstrated that initial ADT treatment led to the apoptosis of endothelial cells and decreased the number of microvascules (Shabsigh et al., 1998). Very intriguingly, microvascules showed regrowth and the number of endothelial cells evidently increased as PCa progressed to the CRPC stage (Godoy et al., 2011; Tomic et al., 2012). This regrowth of microvascules was accompanied by PCa metastasis. Indeed, in vitro evidence supported the notion that endothelial cells could increase PCa cell migration and invasion. By coculturing HUVECs (human umbilical vein endothelial cells) with PCa cells, Chang et al. found that HUVECs had the capacity to enhance cell migration and cell invasion of CWR22Rv1 and C4-2 cells (Wang et al., 2013). According to their data, PCa cells exposed to HUVECs expressed lower levels of AR than non-exposed controls. AR seemingly regulated TGF $\beta$ and MMP9 in a negative manner, as evidenced by the enhanced expression levels of TGF $\beta$ and MMP9 when AR was depleted by siRNAs. They also identified that IL-6, a cytokine secreted by HUVECs, was sufficient to drive AR downregulation. Consistent with this report, HUVECenhanced cell invasion of PCa cells via downregulating the AR level was also observed by Jiang et al. AR reduction was promoted by the interaction of CCL5 on endothelial cells with its receptor CCR5 on PCa cells, triggering mitochondriamediated autophagy, one mechanism responsible for cell invasion of PCa cells (Zhao et al., 2018). Interestingly, another study documented that MMP9, together with PIP5K1 $\alpha$, could interact with $\mathrm{AR}$ to promote its transcriptional activity on the downstream target cyclin A1, leading to enhanced growth of 


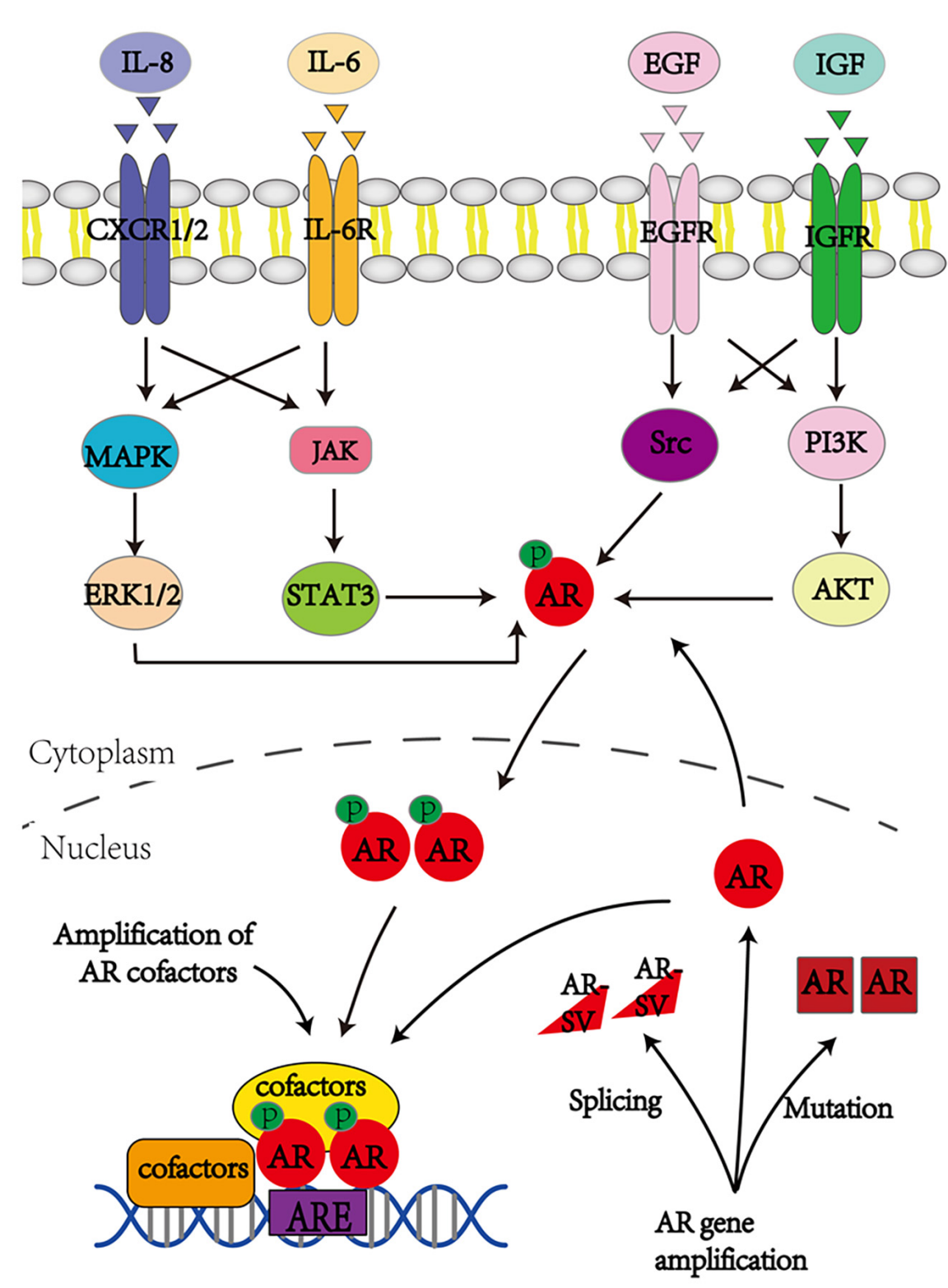

CRPC

FIGURE 2 | Androgen receptor utilizes various ways to bypass AR inhibition to support CRPC growth. P stands for phosphorylation.

metastatic CRPC tumor (Larsson et al., 2020). However, as a transcription factor, how AR regulates TGF $\beta$, MMP9, and autophagy in the presence of HUVECs is still largely unknown and requires further exploration. In addition, it remains to be clarified how IL-6 and CCL5/CCR5 signals at a molecular level reduce AR expression.

On the other hand, anti-androgen-resistant $\mathrm{PCa}$ tends to express a higher level of endothelial nitric oxide synthase (eNOS) compared to hormone naive PCa (Yu et al., 2013), suggesting that chronic inhibition of AR signaling causes an upregulation of eNOS, a critical molecule involved in supporting endothelial cell survival and proliferation. Together, all these data pinpoint a positive feedback loop between PCa cells and endothelial cells during PCa development.

How does AR function in endothelial cells? Literature revealed that androgen could promote cell proliferation of HUVECs by activating the AR/VEGF/Cyclin A signaling axis (Cai J. et al., 2011; Torres-Estay et al., 2017; Eisermann et al., 2013). However, another study contradictorily showed that AR activation triggered TNF- $\alpha$-induced cell apoptosis of EA.hy926 endothelial cells (Ling et al., 2002). One possible explanation to this is that different endothelial cell lines have distinct 
TABLE 1 | Androgen receptor targeted therapies in prostate cancer.

\begin{tabular}{|c|c|c|c|}
\hline Established therapies & AR based drugs & Type of PCa & Mechanistic action \\
\hline LHRH agonists & $\begin{array}{l}\text { Leuprolide; Leuprolide mesylate; } \\
\text { Triptorelin; Goserelin; Histrelin }\end{array}$ & Localized & $\begin{array}{l}\text { Suppress LHRH expression and reduce the } \\
\text { production of FSH and LH. Impair androgen } \\
\text { synthesis in testes }\end{array}$ \\
\hline LHRH antagonists & Degarelix; Relugolix & Localized; Advanced & $\begin{array}{l}\text { Compete LHRH to bind its receptor and } \\
\text { prevent its biological function }\end{array}$ \\
\hline \multirow[t]{2}{*}{ CYP17 inhibitors } & $\begin{array}{l}\text { Abiraterone; TAK-700 (Orteronel); } \\
\text { Ketoconazole; }\end{array}$ & mCRPC & $\begin{array}{l}\text { Inhibition of biosynthesis of adrenal androgens } \\
\text { by suppressing CYP17 activity }\end{array}$ \\
\hline & TOK-001 (Galeterone) & CRPC & \\
\hline \multirow[t]{4}{*}{ Antiandrogen } & Bicalutamide; Nilutamide; Flutamide & Localized; Advanced & $\begin{array}{l}\text { First generation antiandrogen, compete } \\
\text { androgen to interact with AR }\end{array}$ \\
\hline & Enzalutamide & mCRPC & $\begin{array}{l}\text { Second generation antiandrogen, compete } \\
\text { androgen to interact with AR, block AR nuclear } \\
\text { translocation, inhibit AR DNA binding and the } \\
\text { recruitment of AR cofactors }\end{array}$ \\
\hline & Apalutamide (ARN-509) & mCSPC & \\
\hline & Darolutamide & $\mathrm{nmCRPC}$ & \\
\hline
\end{tabular}

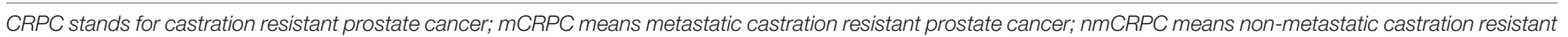
prostate cancer; mCSPC stands for metastatic castration sensitive prostate cancer.

responses to androgen treatment. Therefore, the exact role of $\mathrm{AR}$ in endothelial cells during PCa progression is still open to investigation.

\section{INTERACTION BETWEEN BONE MARROW MESENCHYMAL STEM CELLS AND ANDROGEN RECEPTOR SIGNALING IN PROSTATE CANCER}

An observation of the migration of mesenchymal stem cells (BM-MSCs) into PCa stroma implies their possible participation in the regulation of PCa development (Placencio et al., 2010; Brennen et al., 2017). As multipotent stromal cells, BMMSCs bear the ability to differentiate into various cell types (Pittenger et al., 1999; Mendez-Ferrer et al., 2010) including fibroblasts, adipocytes, and smooth muscle cells in PCa stroma. Moreover, the recruited BM-MSCs promoted cell invasion and stemness differentiation of PCa cells, ultimately allowing PCa cells to survive in an androgen-independent manner (Chang et al., 2014; Luo et al., 2014, 2015). Mechanistic dissection illustrated that BM-MSCs could secrete CCL5 and IL-1 $\beta$, which independently acted to reduce the AR level. According to the literature, secreted CCL5 from BM-MSCs led to decreased levels of prolyl hydroxylase (PHD) 1 and 4, which prevented the hydroxylation of HIF $2 \alpha$ and caused it to become more stable (Luo et al., 2015). Immunoprecipitation assay also confirmed that CCL5-induced HIF2 $\alpha$ enhanced HSP70-AR interaction, which inhibited AR nuclear translocation and the subsequent transactivation. Another study also verified that conditioned medium from BM-MSCs could decrease the AR protein level, which was mediated by the cytokine IL-1 $\beta$ (Chang et al., 2014). However, the detailed mechanism by which IL-1 $\beta$ decreased AR was not clearly explored. These studies also proved that the reduction of AR was a central driving force to promote PCa cell invasion. Further explorations revealed that AR downregulation by BM-MSCs increased the stemness of PCa, owing to the upregulation of several CSC (cancer stem cells) related markers such as CXCR4, ZEB1, and Snail1 (Luo et al., 2014). Given the fact that prostatic CSCs are more malignant than parental $\mathrm{PCa}$ cells, it is understandable that $\mathrm{BM}-\mathrm{MSC}$ promote $\mathrm{PCa}$ invasion and metastasis.

Of note, a lack of evidence showing that AR in BM-MSCs exerts its function to regulate PCa survival and invasion may prompt scientists to explore this direction.

\section{INTERACTION BETWEEN ANDROGEN RECEPTOR SIGNALING IN CANCER-ASSOCIATED FIBROBLASTS AND PROSTATE CANCER}

Cancer-associated fibroblasts (CAFs), one type of activated fibroblasts, typically express high levels of $\alpha$ SMA ( $\alpha$-smooth muscle actin) and fibroblast activation protein (FAP; Sahai et al., 2020). Studies indicate that CAFs have a malignant property by affecting their surrounding compartments including cancerous cells and other stromal cells (Taylor et al., 2012). Compared to normal fibroblasts, CAFs have distinct genome-wide DNA methylation signatures at enhancers and promoters, causing aberrant expression of cancer-related genes to impact cancer fate (Pidsley et al., 2018). Abundant studies show that CAFs exist in the primary site of localized or metastatic PCa microenvironment and promote its initiation and progression. By comparing immortalized CAFs and normal prostate fibroblasts, researchers noticed that CAFs had stronger ability to promote malignant transformation of BPH-1 cells in vitro and in vivo ( $\mathrm{Yu}$ et al., 2017), suggesting that CAF was a central driving source for PCa initiation. In this process, AR in stromal fibroblasts but not in epithelium is necessary for prostatic epithelia malignant 
transformation (Ricke et al., 2012). According to this study, loss of stromal AR did not impair prostate homeostasis but decreased the expression levels of several stroma fibroblast-derived growth factors such as FGF-2 and FGF-10, impeding PCa carcinogenesis (Ricke et al., 2012). Moreover, studies also indicated that CAFs had better capacity to increase cell proliferation and invasion of LNCaP cells in vitro (Yu et al., 2017), compared to normal prostate fibroblasts. The LNCaP xenografted mouse model also strengthened the tumor-promoting role of CAFs in PCa carcinogenesis ( $\mathrm{Yu}$ et al., 2017). Consistent with this report, another study also found that CAFs significantly enhanced PCa growth and distant metastases when compared to normal prostate fibroblasts (Linxweiler et al., 2020). Why are CAFs so effective in promoting PCa development? Focus cytokine array showed that CAFs secreted more growth factors such as EGF, FGF, HGF, TGF $\beta$ and VEGF, than normal prostate fibroblasts, providing survival advantage to PCa cells (Yu et al., 2017).

How does AR contribute to fibroblast proliferation and migration? Results from mouse embryo fibroblasts NIH3T3 and fibrosarcoma HT1080 revealed that androgen stimulation (10 $\mathrm{nM})$ could suppress proliferation while increasing migration of these two cell lines (Castoria et al., 2014). Mechanistic dissection unfolded that the androgen-stimulated AR/FlnA complex led to the activation of Racl as well as its downstream effector DYRK 1B, which phosphorylated p27 at Ser 10. The phosphorylated p27 at Ser 10 was stabilized and attributable to cell cycle arrest at G0/G1 of fibroblasts (Castoria et al., 2014). Meanwhile, the AR/FlnA complex also triggered the activation of focal adhesion kinase FAK, Rac1, and paxillin via recruiting integrin beta 1, promoting cell migration of NIH3T3, HT1080 cells, and PCa-derived fibroblasts (Castoria et al., 2011; Di Donato et al., 2021). These findings suggest the therapeutic value of targeting the AR/FlnA complex to suppress the malignant activity of CAFs. Indeed, knockdown of FlnA with siRNAs or inhibition of AR by enzalutamide could abolish the migration and invasiveness of CAFs induced by androgen treatment (Di Donato et al., 2021). Similarly, disruption of the AR/FlnA complex by drug-like compound $\mathrm{Rh}-2025 \mathrm{u}$-stapled peptide, which was developed from the AR amino acid sequence required for the interaction with FlnA (Loy et al., 2003; Castoria et al., 2011), abolished the androgen-induced migration and invasiveness of CAFs, consequently leading to less recruitment of CAFs to $\mathrm{PCa}$ and suppressing PCa-CAF organoid growth (Di Donato et al., 2021). How does AR in CAFs function to influence PCa growth and invasion? Several studies have demonstrated that the reduced expression level of $\mathrm{AR}$ in CAFs was a prognostic indicator of $\mathrm{PCa}$ progression, suggesting that $\mathrm{AR}$ in CAFs serves as a negative regulator to determine PCa development. A study showed that AR regulated extracellular matrix (ECM) components and maintained its inhibition on PCa cell invasion. Loss of AR in fibroblasts led to the downregulation of adhesive proteins such as FBXO32 and FBN1 as well as the upregulation of ECM-degrading enzyme MMP1, establishing an environment permissive for PCa cells to invade (Leach et al., 2015). By using the in vitro coculture system, Smith and colleagues found that immortalized human prostate myofibroblast cell line PShTert with AR activation could retard the cell growth of various PCa cells including PC3, Du145, C4-2B, and LNCaP cells, highlighting the protective role of $\mathrm{AR}$ in CAFs during $\mathrm{PCa}$ development (Palethorpe et al., 2018). Additionally, another report further proved that loss of $\mathrm{AR}$ in CAFs promoted cell migration of PCa cells (Cioni et al., 2018). As described in this report, AR negatively regulated the expressions of CCL2 and CXCL8 at the transcriptional level. Therefore, loss of AR released its inhibitory regulation on these two cytokines, which were secreted and promoted PCa cell migration in a paracrine manner. Another document strengthened this conclusion by pinpointing that loss of AR in CAFs led to the enhanced expression levels of interferon gamma (IFN- $\gamma$ ) and macrophage colony-stimulating factor (M-CSF), which acted on PCa cells and educated them to differentiate into cancer stem-like cells (Liao et al., 2017) characterized with more invasive properties. Contradictorily, the group of Chang illustrated that myofibroblast stromal cell line WPMY-1 with AR siRNAs could suppress the cell invasion of PCa cells in the coculture system (Niu et al., 2008), and the group of Gross described that reduction of AR in CAFs with antisense oligonucleotide (ASO) dramatically suppressed CAF-promoted PCa growth in vitro and in vivo (Liao et al., 2017). It can be argued that the group of Chang reached the conclusion on the basis of an artificial coculture system. In the study by Gross, ASOs were utilized to reduce the AR protein level, while the previous study applied anti-androgen RD162 for AR inhibition. It is possible that the physiological effects of anti-androgen and ASO on CAFs are different so that opposite conclusions are generated. Besides, Gross et al. utilized mouse CAFs as a source to study their contribution to the cell growth of human PCa cells, which was not an optimal in vitro model.

Although AR signaling is very important for PCa growth and metastasis, few studies examined AR status in PCa epithelial cells that interprets the signal from CAFs to influence PCa epithelial cells when these two types of cells are communicating with each other, which should be explored with future efforts.

\section{ANDROGEN RECEPTOR SIGNALING IN CROSS TALKS BETWEEN IMMUNE CELLS AND PROSTATE CANCER}

Infiltration of immune cells into PCa is frequently observed, which is further increased upon ADT treatment, indicating that immune cells are actively involved in PCa progression. Macrophages, T lymphocytes, NK cells, and mast cells are the most important components of immune cells, and their cross talk with AR signaling in PCa will be summarized as follows.

\section{ANDROGEN RECEPTOR SIGNALING IN CROSS TALK BETWEEN CD4+T CELLS AND PROSTATE CANCER}

T cells consist of CD8 + cytotoxic T cells and CD4 + helper $\mathrm{T}$ cells, playing a central role in the adaptive immune response. Kwon et al. demonstrated that androgen ablative therapy (ADT) could increase the infiltration of $\mathrm{CD} 4+\mathrm{T}$ cells but not 
CD8 + T cells into the PCa (Mercader et al., 2001). In agreement with this observation, Underwood et al. also found that the infiltration of CD4 $+\mathrm{T}$ cells was strongly associated with poor outcome in PCa patients (McArdle et al., 2004). Collectively, all these findings suggest that $\mathrm{CD} 4+\mathrm{T}$ cells may participate in PCa progression. Consistently, another study documented that androgen (testosterone) could inhibit the differentiation of CD4 + T cells (Kissick et al., 2014). CD4 + T cells isolated from castrated mice exhibited reduced STAT4 phosphorylation and IFN- $\gamma$ production upon testosterone treatment. Testosterone activated AR to transcriptionally upregulate the expression level of Ptpn1 (protein tyrosine phosphatase non-receptor type 1), which in turn served as a negative regulator of STAT4 signaling (Kissick et al., 2014). Therefore, castration not only increased the infiltration of CD4 $+\mathrm{T}$ cells but also promoted their differentiation. Collectively, these data suggest that CD4 $+\mathrm{T}$ cells may play a tumor-promoting role in PCa development. Indeed, through an in vitro cell model, Chang et al. found that PCa cells had a better capacity to recruit CD $4+\mathrm{HH}$ and Molt-3 T cells compared to normal prostate epithelial RWPE1 cells (Hu et al., 2015). Mechanistically, FGF11 secreted from $\mathrm{HH}$ and Molt-3 $\mathrm{T}$ cells led to the reduction of AR in PCa cells by enhancing miR-541-mediated AR mRNA degradation (Hu et al., 2015). AR downregulation could elevate the MMP9 expression level, promoting PCa invasion and metastasis. Again, detailed mechanisms underlying AR regulation of MMP9 were not investigated in this study. In addition, it was unlikely that FGF11 directly increased the expression level of miR-541 to reduce the AR level. PCa cells must undergo multiple signaling events upon FGF11 treatment to complete miR-541 induction.

Although ADT with enzalutamide treatment initially increased the infiltration of CD4 + helper cells, it sensitized PCa cells to CD8 + T cell killing by downregulating the expression of antiapoptotic gene NAIP (neuronal apoptosis inhibitory protein) (Ardiani et al., 2014). NAIP played a critical role in conferring the killing ability of CD8 + cytotoxic cells toward $\mathrm{PCa}$ cells. In enzalutamide-resistant PCa, AR signaling was reactivated in various ways so that $\mathrm{AR}$ drove NAIP expression, decreasing the sensitivity of PCa cells to CD8 + cytotoxic cells (Ardiani et al., 2014). Therefore, a combined therapy using T cell immunotherapy with anti-androgen therapy becomes ideal for PCa management (Sanchez et al., 2013).

\section{ANDROGEN RECEPTOR SIGNALING IN CROSS TALK BETWEEN MACROPHAGES AND PROSTATE CANCER}

As the most predominant immune cells within the PCa microenvironment, macrophages play a central role in $\mathrm{PCa}$ development including cell survival, cell invasion, angiogenesis, lineage plasticity, and anti-androgen resistance. Macrophages can be classified into pro-inflammatory/anti-tumoral M1 type and anti-inflammatory/pro-tumoral M2 type. Typically, M2 macrophages, featured with high IL-10 production, increasingly infiltrate PCa, and this infiltration is strongly correlated with PCa aggressiveness (Comito et al., 2014). Studies demonstrated that $\mathrm{PCa}$ could promote differentiation and polarization of macrophages. PCa-derived IL-6, SDF1, and antimicrobial peptide LL-37 (leucin leucin 37) could promote M1-M2 differentiation/polarization (Comito et al., 2014; Cha et al., 2016), which in turn increased PCa invasiveness. Indeed, depletion of M2 macrophages remarkably inhibited tumor progression in various mouse tumor models (Sica et al., 2008), including PCa. Previous studies revealed that there was much more macrophage infiltration in PCa compared to matched normal tissues, monitored by the specific macrophage marker CD68 (Zhu et al., 2006; Fang et al., 2013), suggesting that macrophages may play a role in PCa tumorigenesis. In an experimental setting mimicking in vivo cell-cell interaction, Fang et al. (2013) applied the coculture system using immortalized prostate epithelial cells (RWPE-1) and macrophages (THP-1) to induce prostate tumorigenesis. The results demonstrated that RWPE-1 cells cocultured with THP-1 cells could well differentiate into prostate spheres and had better ability to develop tumor in xenografted mouse models, and strengthening macrophage infiltration can promote PCa tumorigenesis.

Castration further increased the infiltration of M2 macrophages into PCa (Lin et al., 2013; Yuri et al., 2020), and this recruitment of macrophages by ADT may be attributable to CCL2 production from PCa cells (Tsai et al., 2018). One publication illustrated that a transcriptional repressor of CCL2, SPDEF (SAM pointed domain-containing ETS transcription factor), was positively regulated by AR. ADT inactivated AR transcriptional activity to reduce the transcription of SPDEF, which in turn promoted the expression of CCL2. CCL2 bound its receptor CCR2 on macrophages in a paracrine manner and enhanced their recruitment to PCa cells (Tsai et al., 2018). Furthermore, the infiltrated macrophages would enhance PCa invasion/metastasis via downregulating $\mathrm{AR}$ and activating STAT3 signaling. Chang et al. found that coculture of THP-1 with PCa cells led to AR reduction in PCa cells (Izumi et al., 2013). They also identified that PIAS3 was an AR-inducible gene, which was transcriptionally decreased in the presence of THP-1 cells. Without the negative regulator PIAS3, STAT3 signaling was activated and drove PCa invasion/metastasis. Nevertheless, how AR is reduced when PCa cells receive the signals from macrophages remains unknown and requires additional investigation.

Androgen receptor seemingly acts as a tumor-suppressing factor in PCa-associated macrophages. According to Izumi et al. (2013), AR knockdown in THP-1 cells promoted the expression of CCL2, which bound its receptor CCR2 on PCa cells and activated STAT3-mediated EMT (epithelial mesenchymal transition) and cell invasion/metastasis. However, studies also showed that androgen had the capacity to promote M2 macrophage polarization (Becerra-Diaz et al., 2018; Larsson et al., 2020), supporting the tumor-promoting role of AR signaling in $\mathrm{PCa}$-associated macrophages. Indeed, conditioned medium from PMA-activated THP-1 cells with R1881 stimulation could promote cell migration and cell invasion of CWR-R1 PCa cells without affecting their proliferating ability in vitro 
(Cioni et al., 2020). By applying ChIP-seq and Ingenuity Pathway Analysis, they identified that TREM-1 signaling was remarkably enriched in R1881-treated THP-1 cells compared to vehicletreated ones, and AR physically bound to the proximal or distal upstream region of various genes related to TREM1 signaling, implying that $\mathrm{AR}$ transcriptionally regulates the expression levels of these genes to control TREM-1 signaling. Further explorations revealed that several chemokines such as CCL2, CCL7, CCL13, and CXCL8 secreted by R1881-stimulated THP-1 were responsible for PCa migration. Importantly, TREM1 signaling inhibitory peptide LP17 could block the R1881stimulated production of these chemokines in THP-1 cells and attenuate the associated PCa migration.

\section{THE ROLE OF ANDROGEN RECEPTOR IN CROSS TALK BETWEEN NATURAL KILLER CELLS AND PROSTATE CANCER}

Natural killer (NK) cells are cytotoxic lymphocytes which play an important role in the regulation of innate immune response (Vivier et al., 2011; Perera Molligoda Arachchige, 2021). Accumulating evidence suggests that the infiltration of NK cells is greater in PCa than that in normal prostate tissues (Lin et al., 2017; Wu et al., 2020) and castration amplifies this phenomenon. By using the coculture system, Galustian et al. confirmed that PCa cells had a stronger ability to enhance IL-15-mediated expansion and cytotoxicity of NK cells than non-cancerous cell lines (PNT2 and WPMY-1) (Sakellariou et al., 2020), suggesting that the human body applies a protective strategy against PCa by activating NK cells. Accordantly, another study showed that AR could transcriptionally regulate the expression of NK inhibitory ligand LLT1 (lectin-like transcript 1) in PCa cells (Tang et al., 2020). Castration led to a short decline of AR activity so that the LLT1 level was reduced, eventually contributing to the expansion and activation of NK cells.

Specifically, the recruited NK cells could suppress the progression of CRPC by selectively degrading ARv7
(Lin et al., 2017), the most important AR variant determining CRPC growth and drug resistance (Antonarakis et al., 2014; Scher et al., 2016; Wang et al., 2017). NK cells could not only sensitize CRPC cells to anti-androgen treatment but also inhibit cell invasion of CRPC cells. More importantly, the suppression effect of NK cells on CRPC progression could be attenuated by the introduction of ARv7 into PCa cells. NK cells allowed CRPC cells to express high levels of miR-34 and miR-449, which bound the $3^{\prime}$-UTR of ARv7 and caused its degradation (Lin et al., 2017). As the direct downstream effect of ARv7, EZH2 was reduced upon NK cell treatment and was the key causal factor controlling PCa invasion. All these data indicate that targeting ARv7 or EZH2 may overcome CRPC progression.

\section{CROSS TALK BETWEEN MAST CELLS AND PROSTATE CANCER}

Mast cells are immune cells originated from myeloid stem cells. The wide distribution of mast cells across various tissues suggests that they act as key players to regulate a variety of physiological and pathological functions (Halova et al., 2012; Krystel-Whittemore et al., 2015). Typically, mast cells can be classified into intra-tumoral and peri-tumoral mast cells based on their location in specific tissues. Intra-tumoral mast cells exert a protective role to prevent cancer development while peri-tumoral mast cells support tumor growth (Fleischmann et al., 2009). Evidence supports the tumor-promoting role of mast cells in PCa owing to their peri-tumoral addiction (Johansson et al., 2010). Castration with ADT stimulates mast cell recruitment. Chang et al. used the coculture system to identify several chemoattractants including IL8, adrenomedullin (AM), and CCL8 as key molecules indispensable for mast cell recruitment (Dang et al., 2015). Interestingly, the expression levels of these cytokines were tightly regulated by AR. Castrationmediated AR inhibition increased the expression levels of IL8, AM, and CCL8 in PCa cells so that more mast cells were attracted. Their results also revealed that the recruited mast cells

TABLE 2 | The role of AR in PCa stromal cells.

\begin{tabular}{|c|c|c|c|}
\hline Cell type & The role of AR & Effect on PCa & References \\
\hline \multirow[t]{2}{*}{ Endothelial cells } & Is involved in TNF-induced apoptosis & Inhibits progression & Ling et al., 2002 \\
\hline & $\begin{array}{l}\text { Induces VEGF-A and VCAM-1 expression, promotes } \\
\text { proliferation }\end{array}$ & Promotes progression & $\begin{array}{l}\text { Cai J. et al., 2011; Eisermann } \\
\text { et al., 2013; Torres-Estay et al., } \\
2017\end{array}$ \\
\hline CD4 T cells & $\begin{array}{l}\text { Decreases IFN- } \gamma \text { production and suppresses CD } 4 \text { T cell } \\
\text { proliferation }\end{array}$ & Inhibits progression & Kissick et al., 2014 \\
\hline \multirow[t]{4}{*}{ Fibroblasts } & Upregulates FGF-2 and FGF-10 levels & Promotes initiation & Ricke et al., 2012 \\
\hline & $\begin{array}{l}\text { Decreases cell proliferation while increase cell migration } \\
\text { of fibroblasts cells }\end{array}$ & & Castoria et al., 2011, 2014 \\
\hline & $\begin{array}{l}\text { Negatively regulates the expression levels of CCL2, } \\
\text { CCL8, M-CSF and IFN- } \gamma\end{array}$ & Inhibits invasion & $\begin{array}{l}\text { Cioni et al., 2018; Palethorpe } \\
\text { et al., } 2018\end{array}$ \\
\hline & Regulates cytokines secretion & Increases growth invasion & $\begin{array}{l}\text { Niu et al., 2008; Liao et al., } \\
2017\end{array}$ \\
\hline \multirow[t]{2}{*}{ Macrophages } & Negatively regulates the expression levels of CCL2 & Inhibits invasion & Izumi et al., 2013 \\
\hline & $\begin{array}{l}\text { Promotes M2 macrophages polarization and regulates } \\
\text { TREM-1 signaling }\end{array}$ & Promotes invasion & $\begin{array}{l}\text { Becerra-Diaz et al., 2018; Cioni } \\
\text { et al., } 2020\end{array}$ \\
\hline
\end{tabular}




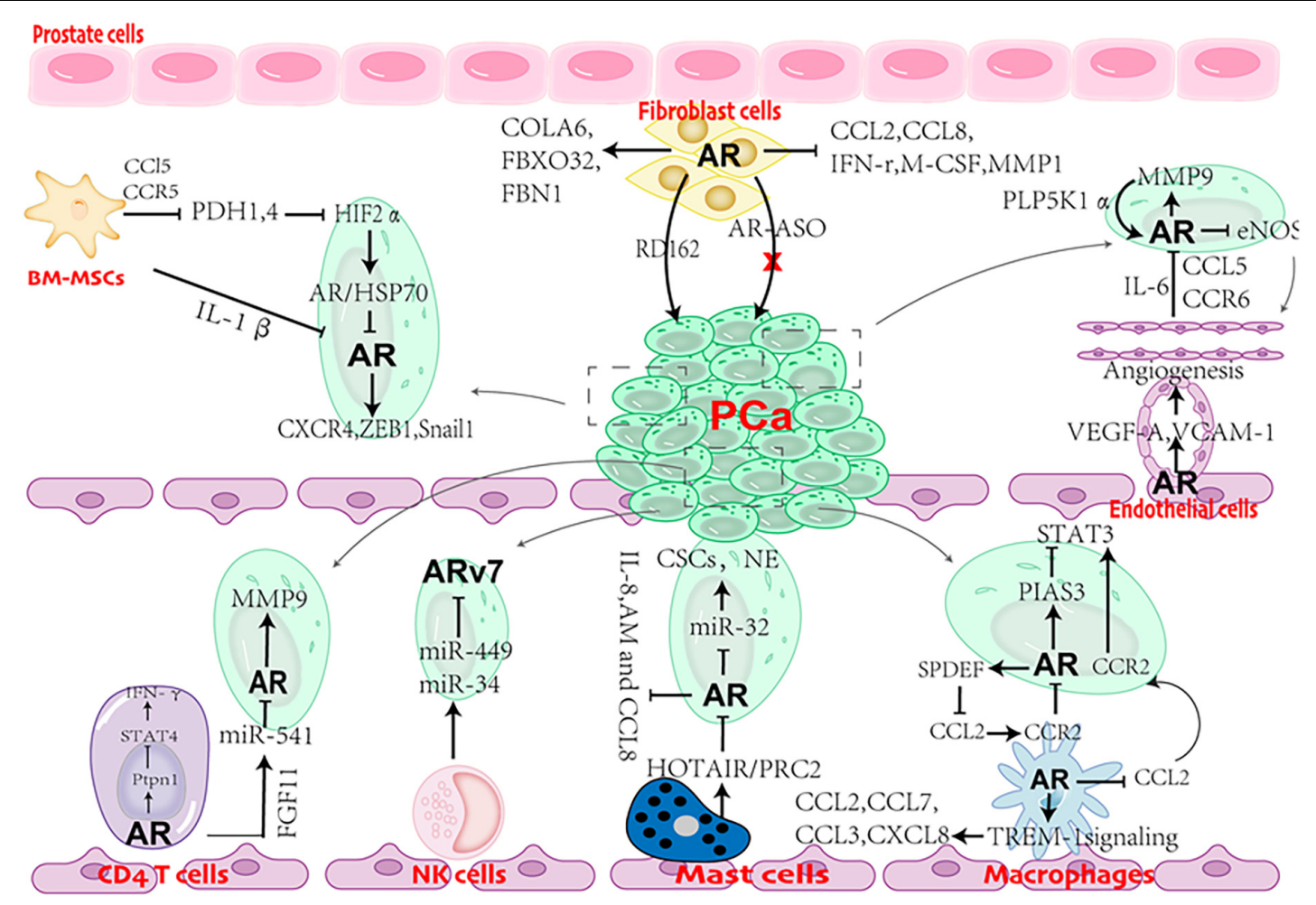

FIGURE 3 | Cartoon showing the role of AR in cross talks between stromal cells and prostate cancer (PCa) cells.

could drive neuroendocrine (NE) and stemness differentiation of PCa cells (Li et al., 2015), promoting cancer invasion and tumor metastasis. According to their data, miR-32 upregulation in PCa after AR inhibition was the causal factor determining NE differentiation. However, the targets of miR-32, potentially the direct downstream effectors regulating NE differentiation, are still not yet identified.

Evidence also revealed that infiltrating mast cells could enhance the occupation of the HOTAIR/PRC2-suppressing complex at the upstream promoter region of the AR gene locus, leading to the suppressive transcription of AR (Li et al., 2015). The exact role of AR in mast cells in regard to $\mathrm{PCa}$ growth and invasion/metastasis is another direction for further investigation.

\section{CONCLUSION AND FUTURE PERSPECTIVE}

Although clinical evidence suggests that stromal AR is gradually lost as PCa progresses to advanced stage, experimental results indicate that the role of $\mathrm{AR}$ in stromal cells is complicated (Table 2) and is still open for investigation. Stromal cells (CAFs, BM-MSCs, endothelial cells, CD4 + T cells, macrophages, NK cells, and mast cells) are clearly observed in PCa and castration with ADT or anti-androgen treatment further increasing the infiltration, leading to AR reduction (Figure 3). Although AR reduction retards $\mathrm{PCa}$ growth, it promotes $\mathrm{PCa}$ cell invasion and tumor metastasis. Further explorations support that AR inhibition increases the populations of cancer stem-like cells and neuroendocrine cells, which are widely viewed as AR negative and lethal type of PCa cells with little response to current treatments. Besides, AR inhibition also releases the transcriptional suppression on MMP9 and multiple cytokines (CCL5, CCL2 IL8, IL-1 $\beta$ and more). These cytokines serve as chemoattractants to recruit stromal cells into PCa. MMP9, as one of matrix metallopeptidases, can degrade the ECM and allow PCa cells to invade. From this point of view, although ADT can slow down PCa tumor growth, it predisposes PCa to undergo malignant transformation. Therefore, a simultaneous inhibition of AR signaling and the supporting stimuli from the surrounding microenvironment or signaling pathways involved in tumor metastasis is a promising therapeutic strategy to battle against PCa progression.

\section{AUTHOR CONTRIBUTIONS}

QT and BC drafted the manuscript. RD and RW oversaw this manuscript. All authors contributed to the article and approved the submitted version.

\section{FUNDING}

This work was supported by the China National Natural Science Foundation (81903113). 


\section{REFERENCES}

Antonarakis, E. S., Lu, C., Wang, H., Luber, B., Nakazawa, M., Roeser, J. C., et al. (2014). AR-V7 and resistance to enzalutamide and abiraterone in prostate cancer. N. Engl. J. Med. 371, 1028-1038.

Ardiani, A., Gameiro, S. R., Kwilas, A. R., Donahue, R. N., and Hodge, J. W. (2014). Androgen deprivation therapy sensitizes prostate cancer cells to T-cell killing through androgen receptor dependent modulation of the apoptotic pathway. Oncotarget 5, 9335-9348. doi: 10.18632/oncotarget.2429

Becerra-Diaz, M., Strickland, A. B., Keselman, A., and Heller, N. M. (2018). Androgen and androgen receptor as enhancers of M2 macrophage polarization in allergic lung inflammation. J. Immunol. 201, 2923-2933. doi: 10.4049/ jimmunol.1800352

Brennen, W. N., Zhang, B., Kulac, I., Kisteman, L. N., Antony, L., Wang, H., et al. (2017). Mesenchymal stem cell infiltration during neoplastic transformation of the human prostate. Oncotarget 8, 46710-46727. doi: 10.18632/oncotarget. 17362

Cai, H., Babic, I., Wei, X., Huang, J., and Witte, O. N. (2011). , Invasive prostate carcinoma driven by c-Src and androgen receptor synergy. Cancer Res. 71, 862-872. doi: 10.1158/0008-5472.can-10-1605

Cai, J., Hong, Y., Weng, C., Tan, C., Imperato-McGinley, J., and Zhu, Y. S. (2011). Androgen stimulates endothelial cell proliferation via an androgen receptor/VEGF/cyclin A-mediated mechanism. Am. J. Physiol. Heart Circ. Physiol. 300, H1210-H1221.

Castoria, G., Auricchio, F., and Migliaccio, A. (2017). Extranuclear partners of androgen receptor: at the crossroads of proliferation, migration, and neuritogenesis. FASEB J. 31, 1289-1300. doi: 10.1096/fj.201601047r

Castoria, G., D’Amato, L., Ciociola, A., Giovannelli, P., Giraldi, T., Sepe, L., et al. (2011). Androgen-induced cell migration: role of androgen receptor/filamin A association. PLoS One 6:e17218. doi: 10.1371/journal.pone.0017218

Castoria, G., Giovannelli, P., Di Donato, M., Ciociola, A., Hayashi, R., Bernal, F., et al. (2014). Role of non-genomic androgen signalling in suppressing proliferation of fibroblasts and fibrosarcoma cells. Cell Death Dis. 5:e1548. doi: $10.1038 /$ cddis. 2014.497

Cha, H. R., Lee, J. H., Hensel, J. A., Sawant, A. B., Davis, B. H., Lee, C. M., et al. (2016). Prostate cancer-derived cathelicidin-related antimicrobial peptide facilitates macrophage differentiation and polarization of immature myeloid progenitors to protumorigenic macrophages. Prostate 76, 624-636. doi: 10. 1002/pros. 23155

Chang, M. A., Patel, V., Gwede, M., Morgado, M., Tomasevich, K., Fong, E. L., et al. (2014). IL-1beta induces p62/SQSTM1 and represses androgen receptor expression in prostate cancer cells. J. Cell Biochem. 115, 2188-2197.

Chen, T., Wang, L. H., and Farrar, W. L. (2000). Interleukin 6 activates androgen receptor-mediated gene expression through a signal transducer and activator of transcription 3-dependent pathway in LNCaP prostate cancer cells. Cancer Res. $60,2132-2135$.

Cioni, B., Nevedomskaya, E., Melis, M. H. M., van Burgsteden, J., Stelloo, S., Hodel, E., et al. (2018). Loss of androgen receptor signaling in prostate cancerassociated fibroblasts (CAFs) promotes CCL2- and CXCL8-mediated cancer cell migration. Mol. Oncol. 12, 1308-1323. doi: 10.1002/1878-0261.12327

Cioni, B., Zaalberg, A., van Beijnum, J. R., Melis, M. H. M., van Burgsteden, J., Muraro, M. J., et al. (2020). Androgen receptor signalling in macrophages promotes TREM-1-mediated prostate cancer cell line migration and invasion. Nat. Commun. 11:4498.

Comito, G., Giannoni, E., Segura, C. P., Barcellos-de-Souza, P., Raspollini, M. R., Baroni, G., et al. (2014). Cancer-associated fibroblasts and M2-polarized macrophages synergize during prostate carcinoma progression. Oncogene 33, 2423-2431. doi: 10.1038/onc.2013.191

Crawford, E. D., and Hou, A. H. (2009). The role of LHRH antagonists in the treatment of prostate cancer. Oncology 23, 626-630.

Dang, Q., Li, L., Xie, H., He, D., Chen, J., Song, W., et al. (2015). Anti-androgen enzalutamide enhances prostate cancer neuroendocrine (NE) differentiation via altering the infiltrated mast cells $->$ androgen receptor (AR) $->$ miRNA32 signals. Mol. Oncol. 9, 1241-1251. doi: 10.1016/j.molonc.2015.02.010

DePrimo, S. E., Diehn, M., Nelson, J. B., Reiter, R. E., Matese, J., Fero, M., et al. (2002). Transcriptional programs activated by exposure of human prostate cancer cells to androgen. Genome Biol. 3:RESEARCH0032.
Di Donato, M., Zamagni, A., Galasso, G., Di Zazzo, E., Giovannelli, P., Barone, M. V., et al. (2021). The androgen receptor/filamin A complex as a target in prostate cancer microenvironment. Cell Death Dis. 12:127.

Dudley, A. C. (2012). Tumor endothelial cells. Cold Spring Harb. Perspect. Med. 2:a006536.

Eisermann, K., Broderick, C. J., Bazarov, A., Moazam, M. M., and Fraizer, G. C. (2013). Androgen up-regulates vascular endothelial growth factor expression in prostate cancer cells via an Sp1 binding site. Mol. Cancer 12:7.

Fang, L. Y., Izumi, K., Lai, K. P., Liang, L., Li, L., Miyamoto, H., et al. (2013). Infiltrating macrophages promote prostate tumorigenesis via modulating androgen receptor-mediated CCL4-STAT3 signaling. Cancer Res. 73, 56335646. doi: 10.1158/0008-5472.can-12-3228

Fleischmann, A., Schlomm, T., Kollermann, J., Sekulic, N., Huland, H., Mirlacher, M., et al. (2009). Immunological microenvironment in prostate cancer: high mast cell densities are associated with favorable tumor characteristics and good prognosis. Prostate 69, 976-981. doi: 10.1002/pros.20948

Godoy, A., Montecinos, V. P., Gray, D. R., Sotomayor, P., Yau, J. M., Vethanayagam, R. R., et al. (2011). Androgen deprivation induces rapid involution and recovery of human prostate vasculature. Am. J. Physiol. Endocrinol. Metab. 300, E263-E275.

Halova, I., Draberova, L., and Draber, P. (2012). Mast cell chemotaxis chemoattractants and signaling pathways. Front. Immunol. 3:119. doi: 10.3389/ fimmu.2012.00119

Heinlein, C. A., and Chang, C. (2004). Androgen receptor in prostate cancer. Endocr. Rev. 25, 276-308.

Henshall, S. M., Quinn, D. I., Lee, C. S., Head, D. R., Golovsky, D., Brenner, P. C., et al. (2001). Altered expression of androgen receptor in the malignant epithelium and adjacent stroma is associated with early relapse in prostate cancer. Cancer Res. 61, 423-427.

Hu, S., Li, L., Yeh, S., Cui, Y., Li, X., Chang, H. C., et al. (2015). Infiltrating T cells promote prostate cancer metastasis via modulation of FGF11-> miRNA541-> androgen receptor (AR)-> MMP9 signaling. Mol. Oncol. 9, 44-57. doi: 10.1016/j.molonc.2014.07.013

Izumi, K., Fang, L. Y., Mizokami, A., Namiki, M., Li, L., Lin, W. J., et al. (2013). Targeting the androgen receptor with siRNA promotes prostate cancer metastasis through enhanced macrophage recruitment via CCL2/CCR2induced STAT3 activation. EMBO Mol. Med. 5, 1383-1401. doi: 10.1002/ emmm.201202367

Johansson, A., Rudolfsson, S., Hammarsten, P., Halin, S., Pietras, K., Jones, J., et al. (2010). Mast cells are novel independent prognostic markers in prostate cancer and represent a target for therapy. Am. J. Pathol. 177, 1031-1041. doi: 10.2353/ajpath.2010.100070

Kissick, H. T., Sanda, M. G., Dunn, L. K., Pellegrini, K. L., On, S. T., Noel, J. K., et al. (2014). Androgens alter T-cell immunity by inhibiting T-helper 1 differentiation. Proc. Natl. Acad. Sci. U.S.A. 111, 9887-9892. doi: 10.1073/pnas. 1402468111

Koivisto, P., Kononen, J., Palmberg, C., Tammela, T., Hyytinen, E., Isola, J., et al. (1997). Androgen receptor gene amplification: a possible molecular mechanism for androgen deprivation therapy failure in prostate cancer. Cancer Res. 57, 314-319.

Krystel-Whittemore, M., Dileepan, K. N., and Wood, J. G. (2015). Mast cell: a multi-functional master cell. Front. Immunol. 6:620. doi: 10.3389/fimmu.2015. 00620

Larsson, P., Syed Khaja, A. S., Semenas, J., Wang, T., Sarwar, M., Dizeyi, N., et al. (2020). The functional interlink between AR and MMP9/VEGF signaling axis is mediated through PIP5K1alpha/pAKT in prostate cancer. Int. J. Cancer 146, 1686-1699. doi: 10.1002/ijc.32607

Leach, D. A., Need, E. F., Toivanen, R., Trotta, A. P., Palethorpe, H. M., Tamblyn, D. J., et al. (2015). Stromal androgen receptor regulates the composition of the microenvironment to influence prostate cancer outcome. Oncotarget 6, 16135-16150. doi: 10.18632/oncotarget.3873

Lepor, H., and Shore, N. D. (2012). LHRH agonists for the treatment of prostate cancer: 2012. Rev. Urol. 14, 1-12. doi: 10.1016/j.eursup.2005.04.002

Li, L., Dang, Q., Xie, H., Yang, Z., He, D., Liang, L., et al. (2015). Infiltrating mast cells enhance prostate cancer invasion via altering LncRNA-HOTAIR/PRC2androgen receptor (AR)-MMP9 signals and increased stem/progenitor cell population. Oncotarget 6, 14179-14190. doi: 10.18632/oncotarget.3651 
Li, Y., Li, C. X., Ye, H., Chen, F., Melamed, J., Peng, Y., et al. (2008). Decrease in stromal androgen receptor associates with androgen-independent disease and promotes prostate cancer cell proliferation and invasion. J. Cell Mol. Med. 12, 2790-2798. doi: 10.1111/j.1582-4934.2008.00279.x

Liao, C. P., Chen, L. Y., Luethy, A., Kim, Y., Kani, K., MacLeod, A. R., et al. (2017). Androgen receptor in cancer-associated fibroblasts influences stemness in cancer cells. Endocr. Relat. Cancer 24, 157-170. doi: 10.1530/erc-16-0138

Lin, S. J., Chou, F. J., Li, L., Lin, C. Y., Yeh, S., and Chang, C. (2017). Natural killer cells suppress enzalutamide resistance and cell invasion in the castration resistant prostate cancer via targeting the androgen receptor splicing variant 7 (ARv7). Cancer Lett. 398, 62-69. doi: 10.1016/j.canlet.2017.03.035

Lin, T. H., Izumi, K., Lee, S. O., Lin, W. J., Yeh, S., and Chang, C. (2013). Antiandrogen receptor ASC-J9 versus anti-androgens MDV3100 (Enzalutamide) or Casodex (Bicalutamide) leads to opposite effects on prostate cancer metastasis via differential modulation of macrophage infiltration and STAT3-CCL2 signaling. Cell Death Dis. 4:e764. doi: 10.1038/cddis.2013.270

Ling, S., Dai, A., Williams, M. R., Myles, K., Dilley, R. J., Komesaroff, P. A., et al. (2002). Testosterone (T) enhances apoptosis-related damage in human vascular endothelial cells. Endocrinology 143, 1119-1125. doi: 10.1210/endo.143.3.8679

Linxweiler, J., Hajili, T., Korbel, C., Berchem, C., Zeuschner, P., Muller, A., et al. (2020). Cancer-associated fibroblasts stimulate primary tumor growth and metastatic spread in an orthotopic prostate cancer xenograft model. Sci. Rep. $10: 12575$.

Liu, Y., Karaca, M., Zhang, Z., Gioeli, D., Earp, H. S., and Whang, Y. E. (2010). Dasatinib inhibits site-specific tyrosine phosphorylation of androgen receptor by Ack1 and Src kinases. Oncogene 29, 3208-3216. doi: 10.1038/onc.2010.103

Lonergan, P. E., and Tindall, D. J. (2011). Androgen receptor signaling in prostate cancer development and progression. J. Carcinog. 10:20. doi: 10.4103/14773163.83937

Loy, C. J., Sim, K. S., and Yong, E. L. (2003). Filamin-A fragment localizes to the nucleus to regulate androgen receptor and coactivator functions. Proc. Natl. Acad. Sci. U.S.A. 100, 4562-4567. doi: 10.1073/pnas.0736237100

Luo, J., Lee, S. O., Cui, Y., Yang, R., Li, L., and Chang, C. (2015). Infiltrating bone marrow mesenchymal stem cells (BM-MSCs) increase prostate cancer cell invasion via altering the CCL5/HIF2alpha/androgen receptor signals. Oncotarget 6, 27555-27565.

Luo, J., Ok Lee, S., Liang, L., Huang, C. K., Li, L., Wen, S., et al. (2014). Infiltrating bone marrow mesenchymal stem cells increase prostate cancer stem cell population and metastatic ability via secreting cytokines to suppress androgen receptor signaling. Oncogene 33, 2768-2778. doi: 10.1038/onc.2013.233

McArdle, P. A., Canna, K., McMillan, D. C., McNicol, A. M., Campbell, R., and Underwood, M. A. (2004). The relationship between T-lymphocyte subset infiltration and survival in patients with prostate cancer. Br. J. Cancer 91, 541-543. doi: 10.1038/sj.bjc.6601943

Mendez-Ferrer, S., Michurina, T. V., Ferraro, F., Mazloom, A. R., Macarthur, B. D., Lira, S. A., et al. (2010). Mesenchymal and haematopoietic stem cells form a unique bone marrow niche. Nature 466, 829-834. doi: 10.1038/nature09262

Mercader, M., Bodner, B. K., Moser, M. T., Kwon, P. S., Park, E. S., Manecke, R. G., et al. (2001). T cell infiltration of the prostate induced by androgen withdrawal in patients with prostate cancer. Proc. Natl. Acad. Sci. U.S.A. 98, 14565-14570.

Migliaccio, A., Castoria, G., Di Domenico, M., de Falco, A., Bilancio, A., Lombardi, M., et al. (2000). Steroid-induced androgen receptor-oestradiol receptor betaSrc complex triggers prostate cancer cell proliferation. EMBO J. 19, 5406-5417. doi: 10.1093/emboj/19.20.5406

Migliaccio, A., Di Domenico, M., Castoria, G., Nanayakkara, M., Lombardi, M., de Falco, A., et al. (2005). Steroid receptor regulation of epidermal growth factor signaling through Src in breast and prostate cancer cells: steroid antagonist action. Cancer Res. 65, 10585-10593. doi: 10.1158/0008-5472.can-05-0912

Montgomery, R. B., Mostaghel, E. A., Vessella, R., Hess, D. L., Kalhorn, T. F., Higano, C. S., et al. (2008). Maintenance of intratumoral androgens in metastatic prostate cancer: a mechanism for castration-resistant tumor growth. Cancer Res. 68, 4447-4454. doi: 10.1158/0008-5472.can-08-0249

Nakazawa, M., Antonarakis, E. S., and Luo, J. (2014). Androgen receptor splice variants in the era of enzalutamide and abiraterone. Horm. Cancer 5, 265-273. doi: 10.1007/s12672-014-0190-1

Niu, Y., Altuwaijri, S., Lai, K. P., Wu, C. T., Ricke, W. A., Messing, E. M., et al. (2008). Androgen receptor is a tumor suppressor and proliferator in prostate cancer. Proc. Natl. Acad. Sci. U.S.A. 105, 12182-12187.
Olapade-Olaopa, E. O., MacKay, E. H., Taub, N. A., Sandhu, D. P., Terry, T. R., and Habib, F. K. (1999). Malignant transformation of human prostatic epithelium is associated with the loss of androgen receptor immunoreactivity in the surrounding stroma. Clin. Cancer Res. 5, 569-576.

Palethorpe, H. M., Leach, D. A., Need, E. F., Drew, P. A., and Smith, E. (2018). Myofibroblast androgen receptor expression determines cell survival in cocultures of myofibroblasts and prostate cancer cells in vitro. Oncotarget 9, 19100-19114. doi: 10.18632/oncotarget.24913

Perera Molligoda Arachchige, A. S. (2021). Human NK cells: from development to effector functions. Innate Immun. 27, 212-229. doi: $10.1177 / 17534259211001512$

Peterziel, H., Mink, S., Schonert, A., Becker, M., Klocker, H., and Cato, A. C. (1999). Rapid signalling by androgen receptor in prostate cancer cells. Oncogene 18, 6322-6329. doi: 10.1038/sj.onc. 1203032

Pidsley, R., Lawrence, M. G., Zotenko, E., Niranjan, B., Statham, A., Song, J., et al. (2018). Enduring epigenetic landmarks define the cancer microenvironment. Genome Res. 28, 625-638. doi: 10.1101/gr.22907 0.117

Pittenger, M. F., Mackay, A. M., Beck, S. C., Jaiswal, R. K., Douglas, R., Mosca, J. D., et al. (1999). Multilineage potential of adult human mesenchymal stem cells. Science 284, 143-147.

Placencio, V. R., Li, X., Sherrill, T. P., Fritz, G., and Bhowmick, N. A. (2010). Bone marrow derived mesenchymal stem cells incorporate into the prostate during regrowth. PLoS One 5:e12920. doi: 10.1371/journal.pone.0012920

Ricciardelli, C., Choong, C. S., Buchanan, G., Vivekanandan, S., Neufing, P., Stahl, J., et al. (2005). Androgen receptor levels in prostate cancer epithelial and peritumoral stromal cells identify non-organ confined disease. Prostate 63, 19-28. doi: 10.1002/pros.20154

Ricke, E. A., Williams, K., Lee, Y. F., Couto, S., Wang, Y., Hayward, S. W., et al. (2012). Androgen hormone action in prostatic carcinogenesis: stromal androgen receptors mediate prostate cancer progression, malignant transformation and metastasis. Carcinogenesis 33, 1391-1398. doi: 10.1093/ carcin/bgs 153

Roumiguie, M., Paoletti, X., Neuzillet, Y., Mathieu, R., Vincendeau, S., Kleinclauss, F., et al. (2021). Apalutamide, darolutamide and enzalutamide in nonmetastatic castration-resistant prostate cancer: a meta-analysis. Future Oncol. 17, 18111823. doi: $10.2217 /$ fon-2020-1104

Ruizeveld de Winter, J. A., Janssen, P. J., Sleddens, H. M., Verleun-Mooijman, M. C., Trapman, J., Brinkmann, A. O., et al. (1994). Androgen receptor status in localized and locally progressive hormone refractory human prostate cancer. Am. J. Pathol. 144, 735-746.

Sahai, E., Astsaturov, I., Cukierman, E., DeNardo, D. G., Egeblad, M., Evans, R. M., et al. (2020). A framework for advancing our understanding of cancerassociated fibroblasts. Nat. Rev. Cancer 20, 174-186. doi: 10.1038/s41568-0190238-1

Sakellariou, C., Elhage, O., Papaevangelou, E., Giustarini, G., Esteves, A. M., Smolarek, D., et al. (2020). Prostate cancer cells enhance interleukin-15mediated expansion of NK cells. BJU Int. 125, 89-102. doi: 10.1111/bju. 14893

Sanchez, C., Chan, R., Bajgain, P., Rambally, S., Palapattu, G., Mims, M., et al. (2013). Combining T-cell immunotherapy and anti-androgen therapy for prostate cancer. Prostate Cancer Prostatic Dis. 16, 123-31,S1.

Scher, H. I., Beer, T. M., Higano, C. S., Anand, A., Taplin, M. E., Efstathiou, E., et al. (2010). Antitumour activity of MDV3100 in castration-resistant prostate cancer: a phase 1-2 study. Lancet 375, 1437-1446.

Scher, H. I., Buchanan, G., Gerald, W., Butler, L. M., and Tilley, W. D. (2004). Targeting the androgen receptor: improving outcomes for castration-resistant prostate cancer. Endocr. Relat. Cancer 11, 459-476. doi: 10.1677/erc.1.00525

Scher, H. I., Lu, D., Schreiber, N. A., Louw, J., Graf, R. P., Vargas, H. A., et al. (2016). Association of AR-V7 on circulating tumor cells as a treatment-specific biomarker with outcomes and survival in castration-resistant prostate cancer. JAMA Oncol. 2, 1441-1449. doi: 10.1001/jamaoncol.2016.1828

Schweizer, M. T., and Antonarakis, E. S. (2012). Abiraterone and other novel androgen-directed strategies for the treatment of prostate cancer: a new era of hormonal therapies is born. Ther. Adv. Urol. 4, 167-178. doi: 10.1177/ 1756287212452196

Seaton, A., Scullin, P., Maxwell, P. J., Wilson, C., Pettigrew, J., Gallagher, R., et al. (2008). Interleukin-8 signaling promotes androgen-independent proliferation 
of prostate cancer cells via induction of androgen receptor expression and activation. Carcinogenesis 29, 1148-1156. doi: 10.1093/carcin/bgn109

Sejda, A., Sigorski, D., Gulczynski, J., Wesolowski, W., Kitlinska, J., and Izycka-Swieszewska, E. (2020). Complexity of neural component of tumor microenvironment in prostate cancer. Pathobiology 87, 87-99. doi: 10.1159/ 000505437

Shabsigh, A., Chang, D. T., Heitjan, D. F., Kiss, A., Olsson, C. A., Puchner, P. J., et al. (1998). Rapid reduction in blood flow to the rat ventral prostate gland after castration: preliminary evidence that androgens influence prostate size by regulating blood flow to the prostate gland and prostatic endothelial cell survival. Prostate 36, 201-206. doi: 10.1002/(sici)1097-0045(19980801)36: $3<201$ ::aid-pros $9>3.0 . \operatorname{co} ; 2-\mathrm{j}$

Sica, A., Larghi, P., Mancino, A., Rubino, L., Porta, C., Totaro, M. G., et al. (2008). Macrophage polarization in tumour progression. Semin. Cancer Biol. 18, 349-355.

Siegel, R. L., Miller, K. D., and Jemal, A. (2020). Cancer statistics, 2020. CA Cancer J. Clin. 70, 7-30.

Smith, D. F., and Toft, D. O. (2008). Minireview: the intersection of steroid receptors with molecular chaperones: observations and questions. Mol. Endocrinol. 22, 2229-2240. doi: 10.1210/me.2008-0089

Tan, M. H., Li, J., Xu, H. E., Melcher, K., and Yong, E. L. (2015). Androgen receptor: structure, role in prostate cancer and drug discovery. Acta Pharmacol. Sin. 36, 3-23. doi: 10.1038/aps.2014.18

Tang, M., Gao, S., Zhang, L., Liu, B., Li, J., Wang, Z., et al. (2020). Docetaxel suppresses immunotherapy efficacy of natural killer cells toward castrationresistant prostate cancer cells via altering androgen receptor-lectin-like transcript 1 signals. Prostate 80, 742-752. doi: 10.1002/pros.23988

Taylor, R. A., Toivanen, R., Frydenberg, M., Pedersen, J., Harewood, L., and Australian Prostate Cancer Bioresource. (2012). Human epithelial basal cells are cells of origin of prostate cancer, independent of CD133 status. Stem Cells 30, 1087-1096. doi: 10.1002/stem.1094

Thienger, P., and Rubin, M. A. (2021). Prostate cancer hijacks the microenvironment. Nat. Cell Biol. 23, 3-5. doi: 10.1038/s41556-020-00616-3

Tilley, W. D., Buchanan, G., Hickey, T. E., and Bentel, J. M. (1996). Mutations in the androgen receptor gene are associated with progression of human prostate cancer to androgen independence. Clin. Cancer Res. 2, 277-285.

Tomic, T. T., Gustavsson, H., Wang, W., Jennbacken, K., Welen, K., and Damber, J. E. (2012). Castration resistant prostate cancer is associated with increased blood vessel stabilization and elevated levels of VEGF and Ang-2. Prostate 72, 705-712. doi: $10.1002 /$ pros. 21472

Torres-Estay, V., Carreno, D. V., Fuenzalida, P., Watts, A., . San Francisco, I. F., Montecinos, V. P., et al. (2017). Androgens modulate male-derived endothelial cell homeostasis using androgen receptor-dependent and receptor-independent mechanisms. Angiogenesis 20, 25-38. doi: 10.1007/s10456-016-9525-6

Tsai, Y. C., Chen, W. Y., Abou-Kheir, W., Zeng, T., Yin, J. J., Bahmad, H., et al. (2018). Androgen deprivation therapy-induced epithelial-mesenchymal transition of prostate cancer through downregulating SPDEF and activating CCL2. Biochim. Biophys. Acta Mol. Basis Dis. 1864, 1717-1727. doi: 10.1016/ j.bbadis.2018.02.016

Visakorpi, T., Hyytinen, E., Koivisto, P., Tanner, M., Keinanen, R., Palmberg, C., et al. (1995). In vivo amplification of the androgen receptor gene and progression of human prostate cancer. Nat. Genet. 9, 401-406. doi: 10.1038/ ng0495-401

Vivier, E., Raulet, D. H., Moretta, A., Caligiuri, M. A., Zitvogel, L., Lanier, L. L., et al. (2011). Innate or adaptive immunity? The example of natural killer cells. Science 331, 44-49.

Waghray, A., Feroze, F., Schober, M. S., Yao, F., Wood, C., Puravs, E., et al. (2001). Identification of androgen-regulated genes in the prostate cancer cell line
LNCaP by serial analysis of gene expression and proteomic analysis. Proteomics 1, 1327-1338. doi: 10.1002/1615-9861(200110)1:10<1327::aid-prot1327>3.0. co;2-b

Wang, R., Sun, Y., Li, L., Niu, Y., Lin, W., Lin, C., et al. (2017). Preclinical study using malat1 small interfering RNA or androgen receptor splicing variant 7 degradation enhancer ASC-J9((R)) to suppress enzalutamide-resistant prostate cancer progression. Eur. Urol. 72, 835-844. doi: 10.1016/j.eururo.2017. 04.005

Wang, X., Lee, S. O., Xia, S., Jiang, Q., Luo, J., Li, L., et al. (2013). Endothelial cells enhance prostate cancer metastasis via IL-6-> androgen receptor-> TGF-beta> MMP-9 signals. Mol. Cancer Ther. 12, 1026-1037. doi: 10.1158/1535-7163. mct-12-0895

Wikstrom, P., Marusic, J., Stattin, P., and Bergh, A. (2009). Low stroma androgen receptor level in normal and tumor prostate tissue is related to poor outcome in prostate cancer patients. Prostate 69, 799-809. doi: 10.1002/pros.20927

Wu, J. D., Haugk, K., Woodke, L., Nelson, P., Coleman, I., and Plymate, S. R. (2006). Interaction of IGF signaling and the androgen receptor in prostate cancer progression. J. Cell Biochem. 99, 392-401.

Wu, Z., Chen, H., Luo, W., Zhang, H., Li, G., Zeng, F., et al. (2020). The landscape of immune cells infiltrating in prostate Cancer. Front. Oncol. 10:517637. doi: 10.3389/fonc.2020.517637I

Yu, S., Jia, L., Zhang, Y., Wu, D., Xu, Z., Ng, C. F., et al. (2013). Increased expression of activated endothelial nitric oxide synthase contributes to antiandrogen resistance in prostate cancer cells by suppressing androgen receptor transactivation. Cancer Lett. 328, 83-94. doi: 10.1016/j.canlet.2012.09. 006

Yu, S., Jiang, Y., Wan, F., Wu, J., Gao, Z., and Liu, D. (2017). Immortalized cancerassociated fibroblasts promote prostate cancer carcinogenesis. Proliferation and Invasion. Anticancer Res. 37, 4311-4318.

Yuri, P., Shigemura, K., Kitagawa, K., Hadibrata, E., Risan, M., Zulfiqqar, A., et al. (2020). Increased tumor-associated macrophages in the prostate cancer microenvironment predicted patients' survival and responses to androgen deprivation therapies in Indonesian patients cohort. Prostate Int. 8, 62-69. doi: 10.1016/j.prnil.2019.12.001

Zhao, R., Bei, X., Yang, B., Wang, X., Jiang, C., Shi, F., et al. (2018). Endothelial cells promote metastasis of prostate cancer by enhancing autophagy. J. Exp. Clin. Cancer Res. 37:221.

Zhu, P., Baek, S. H., Bourk, E. M., Ohgi, K. A., Garcia-Bassets, I., Sanjo, H., et al. (2006). Macrophage/cancer cell interactions mediate hormone resistance by a nuclear receptor derepression pathway. Cell 124, 615-629. doi: 10.1016/j.cell. 2005.12.032

Conflict of Interest: The authors declare that the research was conducted in the absence of any commercial or financial relationships that could be construed as a potential conflict of interest.

Publisher's Note: All claims expressed in this article are solely those of the authors and do not necessarily represent those of their affiliated organizations, or those of the publisher, the editors and the reviewers. Any product that may be evaluated in this article, or claim that may be made by its manufacturer, is not guaranteed or endorsed by the publisher.

Copyright (c) 2021 Tang, Cheng, Dai and Wang. This is an open-access article distributed under the terms of the Creative Commons Attribution License (CC BY). The use, distribution or reproduction in other forums is permitted, provided the original author(s) and the copyright owner(s) are credited and that the original publication in this journal is cited, in accordance with accepted academic practice. No use, distribution or reproduction is permitted which does not comply with these terms. 